chromosomes, namely, Klinefelter's syndrome (Nielsen, 1966).

The literature on the development of malignancy in patients with sex-chromosome abnormalities is not very extensive. Indeed, there is as yet no convincing evidence that abnormalities of sex chromosomes predispose to the development of solid tumours except in the abnormal and rudimentary glands found in these conditions (Goldberg and Scully, 1967; Teter and Bockowski, 1967).

Leukaemia has been described in Turner's syndrome, but the association is not as well documented as in Down's syndrome. Pawliger, Barrow and Noyes (1970) reported one case of acute lymphoblastic leukaemia in a 20 -year-old female and Wertecki and Shapiro (1970) described two cases of acute myeloblastic leukaemia in $45 \mathrm{XO}$ mosaics occurring in a family with a high incidence of twin births.

A search of the literature has revealed no previous report of gastric carcinoma in Turner's syndrome. The connection, if any, between the two conditions must remain speculative, although the unusually early development of the tumour may suggest a genetic predisposition. A chlorhydria, now generally accepted as a pre-malignant condition, is a known association of Turner's syndrome (Grumbach, 1971) but unfortunately gastric acid studies were not performed in this patient.

\section{Acknowledgment}

I wish to thank Dr Nigel Compston for permission to publish this case report.

\section{References}

Goldberg, M.B. \& Scully, A.L. (1967) Gonadal malignancy in gonadal dysgenesis: Papillary pseudomucinous cystadenocarcinoma in a patient with Turner's syndrome. Journal of Clinical Endocrinology, 27, 341.

GrumbaCH, M.M. (1971) The syndrome of gonadal dysgenesis: Turner's syndrome. In: Cecil-Loeb Textbook of Medicine (Ed. by P. B. Beeson and W. McDermott), 13th edn, p. 1800. W. B. Saunders Co., Philadelphia.

JaCKSON, I.M.D., Buchanan, K.D., McKiddie, M.T. \& PrentiCe, C.R.M. (1966) Carbohydrate metabolism and pituitary function in gonadal dysgenesis (Turner's syndrome). Journal of Endocrinology, 34, 289.

NiELSEN, J. (1966) Klinefelter's syndrome and diabetes mellitus. Lancet, ii, 748.

Pawliger, D.F., Barrow, M. \& Noyes, W.D. (1970) Acute leukaemia and Turner's syndrome. Lancet, i, 1345.

TETER, J. \& BockowSKI, K. (1967) Occurrences of carcinoma in dysgenetic gonads. Cancer (N.Y.), 20, 1301.

WERTECKI, W. \& SHAPIRo, J.R. (1970) Acute leukaemia and Turner's syndrome. Lancet, i, 789.

Postgraduate Medical Journal (June 1975) 51, 412-416.

\title{
Secondary syphilis presenting with jaundice
}

\author{
B. K. BHOWMICK \\ M.D., M.R.C.P.
}

\author{
S. P. B. WAY* \\ M.D., B.S., M.R.C.P. \\ Department of Medicine, Burton Road Hospital, Dudley, Worcestershire and \\ * Department of Pathology, Dudley, Stourbridge and District H.M.C.
}

\author{
B. SIMPSON \\ B.Sc., Ph.D., M.B., Ch.B.
}

\section{Summary}

A patient with secondary syphilis presenting with jaundice is reported. Hepatic histology showed evidence of non-specific granuloma and active hepatitis but no cholestasis. This has been treated successfully with antisyphilitic therapy. The possibility of syphilitic pancreatitis and diabetes mellitus is discussed. The importance of serological tests for syphilis in jaundice of obscure origin is emphasized.

\section{Introduction}

The secondary stage of syphilis has always been a diagnostic problem because of protean manifestations. Syphilitic hepatitis is rare and has received scanty attention in the literature. Few histological studies have been reported (Parker, 1972). Hahn
(1943) in a review of the literature could find only eighty cases of hepatitis among 33,825 patients with early syphilis, though in none was the association between the liver disease and the syphilis clearly demonstrated (Baker et al., 1971). Lee, Thornton and Conn (1971) mentioned that they were able to collect only six more patients with early syphilitic hepatitis since 1943. We describe here the case of a patient with secondary syphilis who presented with diabetes mellitus, maculopapular cutaneous rash and jaundice emphasizing the bizarre behaviour of the illness.

\section{Case report}

A 56-year-old white male patient was admitted in March 1973, complaining of tiredness, thirst and 
polyuria for the previous 3 months, and a generalized rash, pruritus, jaundice, dark urine and pale stools for 1 week. He had had no abdominal pain and his appetite had remained very good. There was no history of any serious illness and he had taken no drugs. The patient had not had any injections or blood transfusions, and had never been abroad. He usually consumed only about two pints of beer per week and said that he had been very happily married for 39 years and had one son aged 29 years. There was no family history of diabetes mellitus.

Physical examination revealed moderate jaundice with a generalized red, maculo-papular rash. The liver was palpable $5 \mathrm{~cm}$ below the right costal margin and was firm and non-tender. There was some axillary and inguinal adenitis. Other systems were normal. No penile lesions, mucous patches or condylomata were seen. Proctoscopy revealed normal mucosa.

The urine contained $2 \%$ of sugar, no ketones, a small amount of urobilinogen and a moderate amount of bilirubin.

Laboratory investigations showed normal haemoglobin, white cell count, platelet count and prothrombin time, with an ESR of $90 \mathrm{~mm}$ in the first hour (Westergren). Blood urea and electrolytes were normal. The random blood sugar on admission was $290 \mathrm{mg} / 100 \mathrm{ml}$.

Liver function tests showed a total bilirubin of $10.0 \mathrm{mg} / 100 \mathrm{ml}$, alkaline phosphatase $57.0 \mathrm{~K} . \mathrm{A}$. u/ $100 \mathrm{ml}$, SGOT 62 Frankel u/ml, albumin $3.3 \mathrm{~g} / 100$ $\mathrm{ml}$, globulin $4 \cdot 0 / 100 \mathrm{ml}$, and Kunkel $19 \cdot 0 \mathrm{u}$. Protein electrophoresis showed a dense, discrete band at the front end of the $\gamma$-globulin. When repeated later, a diffuse increase in $\gamma$-globulin was reported. Serum cholesterol was $184 \mathrm{mg} / 100 \mathrm{ml}$. Immunoelectrophoresis showed IgG $1850 \mathrm{mg} \%$, IgA $650 \mathrm{mg} \%$, IgM $325 \mathrm{mg} \%$. Serum amylase was $70 \mathrm{u} / 100 \mathrm{ml}$. Serum iron was $76 \mu \mathrm{g} / 100 \mathrm{ml}$, with a serum total iron binding capacity of $330 \mu \mathrm{g} / 100 \mathrm{ml}$. Hepatitis associated antigen was absent. Paul-Bunnell was negative.

The Reiter protein complement fixation test was positive. The VDRL slide test was positive at a dilution of $1: 256$, and the Cardiolipin Wassermann reaction and the fluorescent treponemal antibody test were also positive, these results strongly suggested a recent treponemal infection.

The faeces contained no occult blood on repeated testing. A barium meal showed a variable area of narrowing, with a deranged mucosal pattern, in the middle of the second part of the duodenum. There was a further, rather variable, extrinsic indentation of its fourth part on its upper border. These appearances were thought to be in keeping with a rather irregular or nodular space-occupying lesion of the pancreas. A cholecystogram was within normal limits.

A percutaneous liver biopsy showed evidence of a hepatitis characterized by pools of polymorphs and lymphocytes quite widely scattered in the liver lobules. In places the liver cells appeared swollen with some large droplet fatty change. At one end of the section there was a small granuloma in which necrotic liver cells and polymorphs, lymphocytes and fibroblasts could be recognized (Fig. 1). A striking feature was the number of vacuolated liver cell

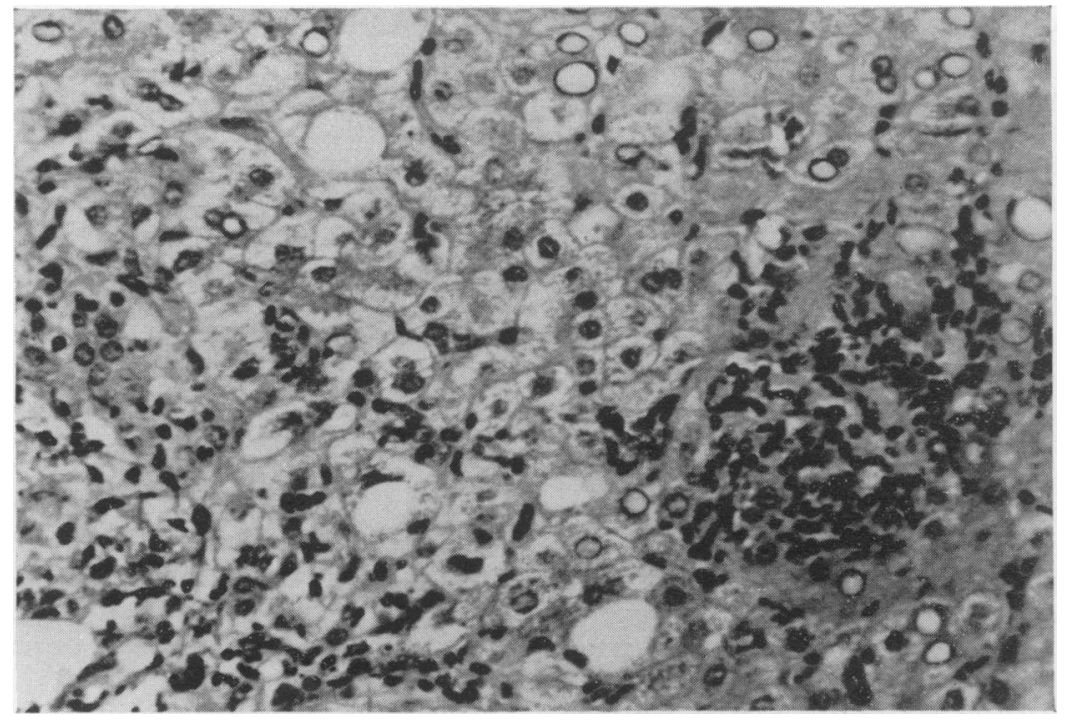

FIG. 1. 


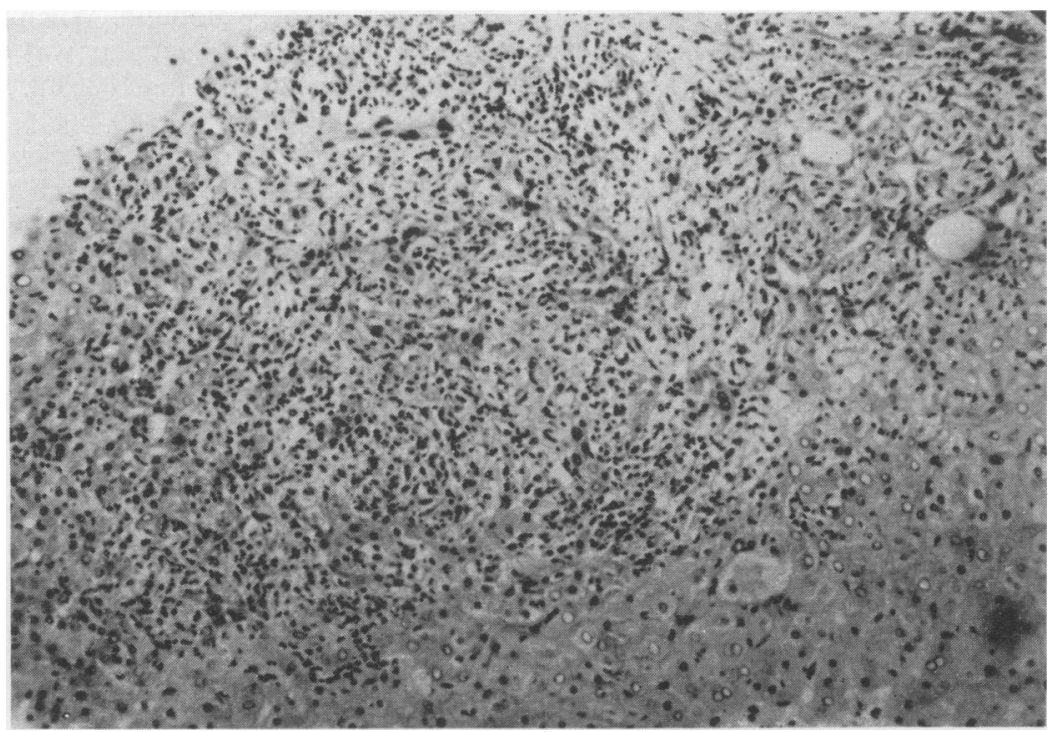

FIG. 2.

nuclei present. These appearances were those of an acute hepatitis such as could be found in secondary syphilis.

The obstructive-type jaundice, with a high ESR, barium meal appearances and associated diabetes, suggested initially the possibility of a carcinoma of the pancreas, and the patient was therefore referred for a surgical opinion. It was on the eve of a laparotomy when the results of the serological tests for syphilis were received. He denied any contact or primary lesions. Also the patient's wife was investigated and proved to be negative. A renewed effort to establish any history of a contact or primary lesion failed.

Treatment was commenced, following the advice of the consultant venereologist, with erythromycin, $500 \mathrm{mg} 6$ hourly for 7 days, then Penidural Long Acting, $2 \cdot 4$ megaunits to commence, followed by procaine penicillin, 900,000 u daily for 13 days, followed by Penidural Long Acting, $1 \cdot 2$ megaunits bi-weekly for 2 weeks. After 2 weeks' treatment, the jaundice continued to fade and the rash disappeared rapidly with some slight scaling of the skin and the liver function tests returned to normal. The diabetes was kept under control with steadily increased doses of soluble insulin and protamine zinc insulin, until antisyphilitic treatment was commenced, when the daily requirement of insulins remained stationary.

A repeated barium meal after 1 month's antibiotic therapy still showed some delay in the passage of barium through the duodenal loop, but on the second part of the loop no organic abnormality was demonstrated. Indentation of the fourth part of the loop on its upper aspect was now less obvious. The appearances suggested that the lesion might have been a pancreatitis which was resolving. An isotopic pancreatic scan at this time revealed a normal pancreas.

When seen 2 months after commencing treatment with antibiotics the patient was feeling very well. $\mathrm{He}$ was not jaundiced and had no lymphadenopathy. Some brown pigmentation marked the sites of the original maculo-papular rash. The liver was not palpable. His diabetes remained well controlled on the same dose of insulin. Serological tests for syphilis showed Wasserman reaction was still positive and VDRL only weakly positive.

\section{Discussion}

Jaundice occurring as an infrequent complication of secondary syphilis has been recognized for 400 years (Wile and Karshner, 1917). Schiff (1963) described hepatic involvement in early syphilis as diffuse liver tenderness or enlargement, less com. monly there is jaundice and abnormality of other liver function tests, though liver disease can occur without jaundice or hepatomegaly (McCracken, Hall and Pierce, 1969). Our patient presented with diabetes mellitus, jaundice, skin rash and nontender hepatomegaly. These findings raised a strong suspicion of carcinoma of the pancreas. A raised sedimentation rate, and the result of the initial barium meal strengthened the suspicion. Serological tests for syphilis, performed because of the rash, strongly suggested a diagnosis of secondary syphilis. Overt jaundice is noted in $5-10 \%$ of cases of glandular fever (Sherlock, 1971b) which can also cause rash and false-positive syphilitic serology. This has 
been excluded by absence of glandular fever cells in peripheral blood and negative Paul-Bunnell. Hepatic histology showed evidence of a granuloma and an active hepatitis. A similar granuloma in secondary stage has been described by Klatskin and Yesner (1950). Other non-specific histological changes reported are portal zone infiltration with polymorphs, cellular degeneration, active cellular regeneration (Lee et al., 1971) and necrotic area extending from the portal tract to the central vein with lymphocytic infiltration (Baker et al., 1971).

The inexplicably high serum alkaline phosphatase in absence of histological cholestasis has been found in all the reported cases of syphilitic hepatitis (Parker, 1972; Baker et al., 1971; McCracken et al., 1969 ) as in this case. A proportional rise of 5-nucleotidase suggested that the increased alkaline phosphatase was of hepatic origin (Lee et al., 1971).

Although hepatitis has been considered to be the direct effect of invasion by spirochaetes (Sherlock, 1971a), a surprising majority of workers failed to demonstrate the presence of these in the liver (Lichtman, 1953). In fact, only in the two patients described by Rajam and Rangiah (1954) and Warthin (1918) were spirochaetes seen in liver tissue. In our patient, hepatic biopsy was undertaken about 1 week after the antisyphilitic therapy and no treponemas were seen in the biopsy specimen. As in other reported cases, following antisyphilitic treatment the liver function tests returned to normal with recession of the hepatomegaly in the present case.

Radiological evidence of duodenal narrowing raised the possibility of Crohn's disease which can also produce granuloma and non-specific histological changes in liver (Dordal, Glagov and Kirsner, 1967), but the complete absence of bowel symptoms along with the serological evidence of recent treponemal infection and dramatic clinical and biochemical improvement following antisyphilitic treatment stand against such a diagnosis. Barium study of the whole intestinal tract, however, was not undertaken.

The diabetes mellitus was probably coincidental. This association has not been described in any of the cases in the literature. The steadily increasing daily insulin requirements until the antisyphilitic treatment was started suggested the possibility of syphilitic involvement of the pancreas; afterwards the dose remained steady, but this could as easily be explained by the controlling of the treponemal infection. Results of two successive barium meal examinations could have been explained by the resolving pancreatitis, but a normal pancreatic scintigram militates against the presence of chronic syphilitic affection. Stokes, Beerman and Ingraham (1944) stated that diabetes due to syphilis, if it exists at all, must be rare. The careful study of 258 cases of combined syphilis and diabetes mellitus reported by McDaniel,
Marks and Joslin (1940) failed to show any aetiological relationship between the two.

It is difficult to say how far the active hepatitis in our patient was contributing to the carbohydrate intolerance. Sherlock (1971) states that blood glucose is usually well maintained even in fulminant hepatitis although cirrhosis of the liver may result in abnormal glucose tolerance.

Although the incidence of syphilis seems to be increasing (American Social Health Association, 1970), well documented cases of syphilitic hepatitis are infrequent. In 1970, over 1000 cases of early infectious syphilis were reported in Great Britain and it is probable that a large number of other cases remained undiagnosed or misdiagnosed (Leading Article, 1972) because of the puzzling ways in which they have presented. This aetiology should be considered in any patient with jaundice of obscure origin since it is so easily treated and since it may well avert an unnecessary laparotomy.

\section{Acknowledgment}

We are grateful to Dr M. M. Kubik, Consultant Physician, Burton Road Hospital, Dudley, for his encouragement and permission to publish this case.

\section{References}

American Social Health Association (1970) Today's V.D. Control Problem. Joint statement of the American Public Health Association, American Social Health Association, American Venereal Disease Association, New York.

Baker, A.L., Kaplan, M.M., Wolfe, H.J. \& McGowan, J.A. (1971) Liver disease associated with early syphilis. New England Journal of Medicine, 284, 1422.

Dordal, E., Glagov, S. \& Kirsner, J.B. (1967) Hepatic lesion in chronic inflammatory bowel disease. Gastroenterology, 52, 239.

HAHN, R.D. (1943) Syphilis of the liver. American Journal of Syphilis and Neurology, 27, 529.

Klatskin, G. \& Yesner, R. (1950) Hepatic manifestations of sarcoidosis and other granulomatous diseases: a study based on histological examination of tissue obtained by needle biopsy of the liver. Yale Journal of Biology and Medicine, 23, 207.

Leading Article (1972) Puzzling cases of secondary syphilis. British Medical Journal, iii, 66.

Lee, R.V., Thornton, G.F. \& ConN, H.O. (1971) Liver disease associated with secondary syphilis. New England Journal of Medicine, 284, 1423.

Lichtman, S.S. (1953) Diseases of the Liver, Gall-bladder and Bile ducts, 2nd edn, p. 876. Henry Kimpton, London.

McCracken, J.D., Hall, W.H. \& Pierce, H.I. (1969) Nephrotic syndrome and hepatitis in secondary syphilis. Military Medicine, 134, 682.

McDaniel, L.T., Marks, H.H. \& Joslin, E.P. (1940) Archives of Internal Medicine, 66, 1011. Quoted in Joslin's Diabetes Mellitus. (Ed. by Alexander Marble.) 11th edn. Lea and Sebiger (1971), Philadelphia.

PARKer, J.D.J. (1972) Uncommon complications of early syphilis. British Journal of Venereal Diseases, 48, 32.

RaJAM, R.V. \& Rangiah, P.N. (1954) Early syphilitic hepatitis. Indian Journal of Venereal Diseases, 20, 83. 
Schiff, L. (1963) Diseases of the Liver, 2nd edn, p. 698. Lippin Co. H., Philadelphia.

SHERLOCK, S. (1971a) The liver in secondary (early) syphilis. New England Journal of Medicine, 284, 1437.

SHERLOCK, S. (1971b) Diseases of the Liver and Biliary System, 4th edn,. p. 620. Blackwell Scientific Publications, Oxford.

Stokes, W.C., Beerman, C.E. \& Ingraham, E. (1944) Modern
Clinical Syphilology, 3rd edn., p. 109. W. B. Saunders Co., Philadelphia.

Warthin, A.S. (1918) The new pathology of syphilis. American Journal of Syphilis and Neurology, 2, 425.

Wile, U.J. \& KARShNER, R.G. (1917) Icterus gravis syphilitics: its relation to acute yellow atrophy Journal of the American Medical Association, 68, 1311.

\title{
Watery diarrhoea and hypokalaemia associated with a phaeochromocytoma
}

\author{
C. A. LOEHRY \\ M.D., B.Chir., M.R.C.P.
}

\author{
J. G. C. KinghaM \\ M.B., B.S., M.R.C.P.
}

\author{
P. J. WHORWELL \\ B.Sc., M.B., B.S., M.R.C.P. \\ Department of Medicine, Royal Victoria Hospital, Bournemouth
}

\begin{abstract}
Summary
The syndrome of water diarrhoea, hypokalaemia and achlorhydria (WDHA) is well described in association with a non-beta islet cell tumour of the pancreas. The following case report is of a 28-year-old woman with a WDHA syndrome that was cured by the removal of a phaeochromocytoma.
\end{abstract}

\section{Introduction}

Since Zollinger and Ellison described their syndrome in 1955 there has been an increasing number of descriptions of gastrointestinal disorders associated with hormone-secreting tumours at various sites. In 1958 Verner and Morrison described a syndrome of watery diarrhoea with hypokalaemia in which non-beta islet cell tumours of the pancreas were present, and there have been many similar cases appearing in the literature since. Achlorhydria is usually, but not always, present. These cases have been designated with various names, the commonest being pancreatic cholera, WDHA syndrome and Verner-Morrison syndrome. A number of hormones have been cited as the causative agent for this syndrome, but there now seems to be evidence that some at least of these may be caused by gastric inhibitory polypeptide (GIP) (Brown and Dryburgh, 1971; Elias et al., 1972; Pedersen and Brown, 1972), or vasoactive intestinal polypeptide (VIP) (Bloom, Poiak and Pearce, 1973). The following hormones and their sites of origin have been incriminated in the production of diarrhoea: gastrin from the gastric antrum or the pancreatic islets (Gregory et al., 1967; Polak, Stagg and Pearce, 1972); 5-hydroxytrypt- amine, kinins and histamine from carcinoid tumours (Oates and Butler, 1967); catecholamines from neural crest tumours, prostaglandins from neural crest tumours and medullary carcinoma of thyroid (Rosenstein and Engelman, 1963; Sandler, Karim and Williams, 1968; Williams, Karim and Sandler, 1968); thyroxine in hyperthyroidism, and histamine in systemic mastocytosis (Denis, 1963). Recently Pearce (1969) has postulated the concept of a series of closely related polypeptide and amine producing cells derived from the neural crest; these he has called APUD cells (amine precursor uptake and decarboxylase). Included amongst these are the antral $G$ cells (gastrin), the small intestinal D, I, S and EG cells (GIP, VIP, secretin and enteroglucagon respectively), the pancreatic islet $\mathrm{B}, \mathrm{A}$, and $\mathrm{D}$ cells (insulin, glucagon and gastrin respectively), the $C$ cells of the thyroid (calcitonin), the corticotrophic and melanotrophic cells of the anterior pituitary (ACTH and MSH respectively), the phaeochromocytes (catechol amines), and the enterochromaffin EC cells (histamine, 5-hydroxytryptamine).

\section{Case report}

A 28-year-old-woman presented in 1968 with a 1year history of watery diarrhoea unassociated with blood or mucus. Examination, sigmoidoscopy and barium enema were unremarkable, and a diagnosis of mild ulcerative colitis was made. She was treated with anti-diarrhoeals and a milk-free diet. Her symptoms continued and the addition of salazopyrin, $1 \mathrm{~g}$ q.d.s. and prednisolone, $15 \mathrm{mg}$ daily produced little improvement. Shortly after this she complained of paroxysmal headaches with preceding palpitations 